EPiC Series in Engineering
Volume 3, 2018, Pages 95-102
HIC 2018. 13th International
Conference on Hydroinformatics

\title{
A multi-hazard Extreme Climate Index across Europe
}

\author{
Elisa Arnone ${ }^{1,2}$, Marco Cucchi $^{1}$, Sara Dal Gesso ${ }^{1}$, and Marcello Petitta ${ }^{1,3,4}$ \\ ${ }^{1}$ AMIGO s.r.l., via Flaminia 48, Rome, I-00196, Italy \\ ${ }^{2}$ Università degli Studi di Palermo, Viale delle Scienze ed., 8, Palermo, 90133, Italy \\ ${ }^{3}$ ENEA, SSPT-MET-CLIM, Roma, Italia \\ ${ }^{4}$ EURAC, Institute for applied remote sensing, Bolzano, Italia \\ elisa.arnonelamigoclimate.com
}

\begin{abstract}
The ECI is a multi-hazard index which has been developed in the context of the eXtreme Climate Facilities (XCF) project lead by ARC (African Risk Capacity) with the objective of detecting the occurrence of climate extremes over the African continent. The main hazards covered by ECI are the extreme dry, wet and heat events. However, the definition of ECI allows for the integration of additional hazards in the same index. The index has been designed and widely tested across Africa. The objective of this study is to test the usability and potential application of the same index under different climate regimes that are typical of the mid-latitudes, including the Mediterranean area and northern Europe. The analysis presented in this study shows that the ECI allows an accurate detection of extreme cold/heat waves as well as events of abundant precipitation across Europe over the last decades
\end{abstract}

\section{Introduction}

In summer 2017, Southern Europe and Euro-Mediterranean regions experienced one of the most extreme heat wave which caused significant social and economic damages. The World Weather Attribution (WWA) provides a comprehensive analysis of the most remarkable aspects of the temperatures in June-August in the Euro-Mediterranean region, and shows the exceptional characteristics of the last summer. January 2017 was instead colder than normal across Central, North-eastern and Eastern Europe, including Italy and the whole Balkan Peninsula (Anagnostopoulou et al., 2017). Heavy and intense precipitations also hit North-eastern Europe in the second half of the year (Severe Weather Europe).

The last assessment report of the Intergovernmental Panel on Climate Change - IPCC-5AR (IPCC, 2013) had claimed that extreme hydro-meteorological events, ranging from heat waves, cold 
spells to extreme rainfall events or ice storms, would have likely increased in intensity, duration and frequency over the upcoming decades. Evidence of positive trends in observed extreme rainfall were demonstrated in the past by several studies for daily and sub-daily timescales (Arnone et al., 2013; Wang et al., 2014), indicating the Mediterranean area among the regions mostly affected by the changes in climate. A further research question is whether or not there is a trend toward increasing temperature and whether or not climate change caused by human activities played a role. Studies based on future projections confirm the trend of increase in extreme rainfall events (Forestieri et al., 2017).

Climate extreme events indeed present a risk for the society and for several economic sectors, e.g., agriculture, water resources, infrastructures, food security, health. Climate information, if opportunely incorporated into multidisciplinary development planning and projects, could enhance decision making within the aforementioned sectors. The need of the scientific community is thus improving the understanding of trends and patterns in extreme climate events and secondly, but not less importantly, providing with useful, efficient and suitable tools which allow for the detection and the prediction of extreme events, even at large scale. Ultimately, these tools can be used to establish financial support and infrastructures to help countries in managing natural disaster risk and adapt to climate change. An example in this direction is given by the international project called eXtreme Climate Facility (XCF) and funded by the African Risk Capacity (ARC), which promoted the development of an advanced and suitable suit of extreme climate indices to track extreme events across the African continent in an objective manner (ARC, 2017). The activities have been carried out by the AMIGO s.r.l. climate company, and led to the development of the multi-hazard Extreme Climate Index (ECI) at regional scale, which has been successfully tested and validated across Africa.

The challenge of this study is to evaluate the multi-hazard index ECI across Europe to provide an objective and easy-accessible tool for the detection of different types of extreme events. Specifically, the target is to assess the capability of this index to capture the severity and frequency of heat and cold waves, droughts and abundant precipitation over an area characterized by different climate regimes.

\section{Methodology}

\subsection{ECI}

The Extreme Climate Index (ECI) is defined by the combination of two types of hazard indicators: the Standardized Precipitation Index (SPI) (Mckee et al., 1993), which accounts for extreme dry/wet events (hydrological component), and a specifically developed index, Standardized Heat-waves Index (SHI) (Cucchi et al., 2017), which accounts for heat events (thermal component). In order to make ECI suitable to describe different types of climatic extremes, a computational strategy to combine the single indicators, and possibly other indices, have been developed by Cucchi et al. (2017). In this study, we used the ECI prototype at three components, which is composed by (i) the 3-month SPI, i.e. SPI3, and (ii) the 12-month SPI, i.e. SPI12, and (iii) the SHI.

SPI is a drought index based on the method developed by McKee et al. (1993). N-months accumulation time windows are used to derive series of cumulative monthly precipitation at $\mathrm{N}$ months (in this case 3 and 12 months). The monthly cumulated distributions are fitted with a gamma distribution; the probabilities are then associated to the inverse normal distribution to compute the index values. In the case of ECI, the two components at two accumulation periods enable for capturing respectively the risks at short time scale, connected with agricultural activities, and at longer time scale, connected to the depletion of reservoirs. 
The SHI is a standardized index based on daily cumulative maximum temperatures. It is derived as a modification of an existing heat-wave index (Russo et al., 2014), already adopted for monitoring heat waves. The computation of SHI is analogous to that of SPI. A 3-days accumulation time window is used to derive a new series of cumulative maximum daily temperature. To remove seasonality, a distribution is fitted to the series for each month. Specifically, it was demonstrated that the split normal distribution is suitable to fit all the empirical distributions. Finally, the inverse normal distribution is applied to compute the values of SHI corresponding to the same probability.

The value of ECI is ultimately defined by three quantities, i.e. the intensity, $\rho$, which indicates the intensity of an event; and the angular components, $\varphi$ and $\theta$, which represent the relative contribution of each indicators to the overall magnitude of the index:

$$
\left\{\begin{array}{c}
\rho=\sqrt{\mathrm{SPI}^{2}+\mathrm{SPI}^{2}+\mathrm{SHI}^{2}} \\
\varphi=\tan ^{-1}\left(\frac{\mathrm{SPI} 12}{\mathrm{SPI} 3}\right) \\
\theta=\tan ^{-1}\left(\frac{\mathrm{SHI}}{\sqrt{\mathrm{SPI}^{2}+\mathrm{SPI}_{2} 2^{2}}}\right)
\end{array}\right.
$$

The number of angular components depends on the number of single-hazard indicators (three in this case). Adding more variables results in having more angular components, hence it is possible to include more hazard indicators in the definition of ECI without changing its overall properties.

ECI is composed of standardized single-hazard indicators, each of which has a standard normal distribution. Its definition, combined with its component properties, make ECI a standardized index itself, with a well-defined chi-squared probability distribution function. ECI can be therefore used to identify extremes after defining a suitable threshold above which events are held as extremes.

\subsection{ECI}

Once the ECI is computed at the spatial resolution of input data, it could turn useful to aggregate regions based on specific criteria. Normally, areas with similar climate regimes are aggregated, by using the Ward's method for cluster analysis (Ward, 1963), which has proven to yield useful insight in the data analysis of climate data and weather typing (Wilks, 2006). The goal of cluster analysis is to detect objects (e.g. time series or spatial patterns) sharing some selected properties and to group them into homogeneous subsets. This approach was used by Cucchi et al., (2017) in the context of XCF, to aggregated regions with similar climate regimes over Africa, which will benefit from the same adaptation measures. In the case of Europe, we choose to aggregate regions based on the administrative limits of each country. In fact, because the ultimate use of the index may be within a climate risk management system which can be adopted at national level, it turns useful providing ECI series that are representative of the entire country. Values of single hazard indicators are aggregated over each country by computing the mean value, and the country-based ECI series index is derived.

\section{Application and Data}

Two types of data are required to derive the ECI components: (i) daily maximum temperature to compute the SHI and (ii) monthly total precipitation to compute the SPI3 and SPI12. 
For both the variables, data have been retrieved from the reanalysis ERA-Interim dataset developed by the European Centre for Medium-Range Weather Forecasts (ECMWF). Data are available from 1979 to present, and the spatial resolution is approximately $80 \mathrm{~km}$. Although significant bias with satellite observations have been ascertained in daily total precipitation, the use of ERA-Interim precipitation is likely appropriate for the aim of this study.

The analysis is carried out across Europe, which is characterized by various climate regimes, mostly Mediterranean, differently temperate and boreal in the most northern part. For the entire area under study, the period of consistent data is from 1983 to 2017, thus considered in this research. Such a long period of data will allow future analyses of detection in extreme changes.

Year 2017 was critical for both precipitation and temperature, with many areas recording extremes. As a demonstration, Figure 1a depicts the relative change of precipitation recorded in 2017 compared to the Mean Annual Precipitation (MAP; 1983-2016). It is noticeable that the Mediterranean area, but the Balkan zone, experienced a decrease in precipitation up to the $50 \%$; northern Europe, such as Norway, Ireland, western UK, recorded more abundant precipitation than usual. Figure 1b depicts the relative change of the mean maximum temperature recorded in 2017 compared to the Mean Annual Temperature (MAT). Most part of Europe has been interested by an increment in the maximum temperature, which reaches almost the $2 \%$ in the Iberian peninsula.
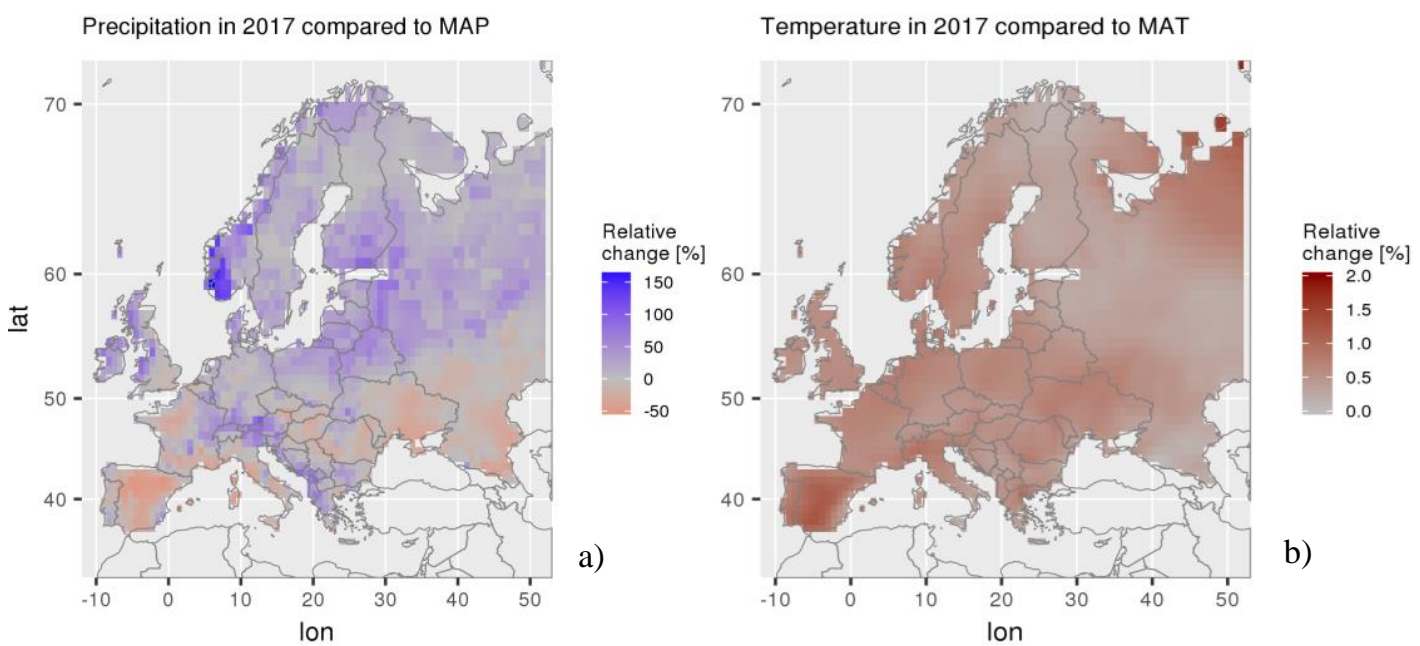

Figure 1: (a) Relative change of precipitation recorded in 2017 compared to the Mean Annual Precipitation (MAP). (b) relative change of the mean maximum temperature recorded in 2017 compared to the Mean Annual Temperature (MAT).

\section{Results}

To identify extremes occurrences, we first define a threshold in the ECI series. An event is labelled as extreme when the associated ECI value overcomes the threshold. Specifically, we identify two thresholds defined as the $95 \%$ and the $99 \%$ percentile over the entire ECI dataset (in time and space), corresponding to 2.82 and 3.56 respectively. The validity of a single threshold for the entire area is made possible by the standardization properties of the index.

Figure 2a depicts the spatial distribution of the percentage of extreme occurrences over the last decade (2010-2017), which is remembered as one of the periods with high frequency of extremes. The figure highlights the areas where the extreme occurrence is higher, such as part of the 
Scandinavian peninsula (e.g., Norway, Finland), Ireland and western UK, the Balkans coast, Poland, and the Italian and Austrian Alps. Figure $2 b$ shows the spatial distribution of the extreme occurrences in 2017. The map clearly highlights the areas characterized by the high frequency of severe events, with a percentage of occurrences greater than the $50 \%$. This means that, for those areas, the ECI value overcome the threshold for most of the time in 2017. Again, Norway, the Balkan areas, Ireland, the Italian and Austrian Alps and the centre of Europe are the identified areas most frequently hidden by extreme events.
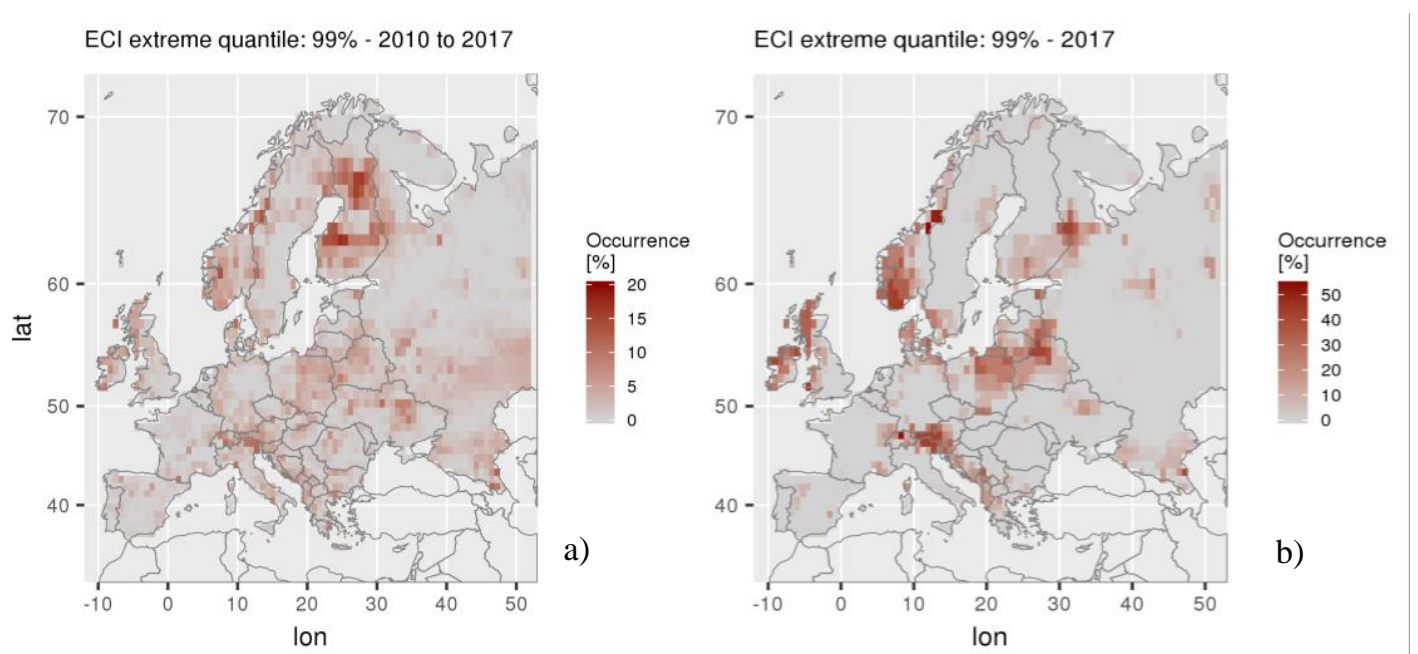

Figure 2: Percentage of extreme occurrences (ECI greater than $99 \%$ quantile threshold) across Europe in (a) 2010-2017 and (b) 2017.

To assess the type and the severity of the extreme events, it turns useful analysing the ECI time series for some of the aforementioned countries (Figure 3 to Figure 5). The 95\% and 99\% ECI quantiles thresholds are reported. The shaded-grey rectangles highlight the analysed extreme events.

In mid-2017, the ECI series for Norway significantly jumps to very extreme values (Figure 3). High ECI values are determined mainly by the contribution of SPI3 and SPI12 while the SHI does not show significant differences from the mean. Historical observations confirmed that, in fact, in July 2017 abundant and intense precipitations caused major floods in western Norway; raingauged recorded about $28 \mathrm{~mm}$ in 1 hour and almost $80 \mathrm{~mm}$ in 24 hours (NFFS, 2017). In October 2017, southern Norway experienced the worst flooding on record, with massive rain levels (Langsholt and E. Holmqvist, 2017). Other extremes captured by the ECI occurred, for example, in late 2010 and late 2011 (shades-grey areas). The former describes a cold wave (i.e. extreme negative values of SHI together with 'normal' SPI indices) whereas the latter denotes a heat wave (extreme positive values of SHI and 'normal' SPI indices). It is worth reminding that, by definition, events are considered as extremes when temperature or precipitation are significantly different from the climatological mean of the specific month of the year.

Figure 4 shows the time series for Albania with a zoom on the period 2016-2017. Three different types of extreme events are clearly detected by the ECI series: temperatures higher than the seasonal mean at early 2016; temperatures significantly lower than the seasonal mean at the beginning of 2017; abundant precipitation at the end of the last year. The heat wave that hit Europe last summer (WWA, 2017), is associated to an ECI greater than the $95 \%$ percentile threshold. Whereas, heavy rainfall affected the territory of Albania from the 29th November to 4th December 2017 (IFRC, 2017), which caused severe floods in several areas. In some areas, rainfall reached $130 \mathrm{~mm}$ in two hours (IFRC, 2017). 


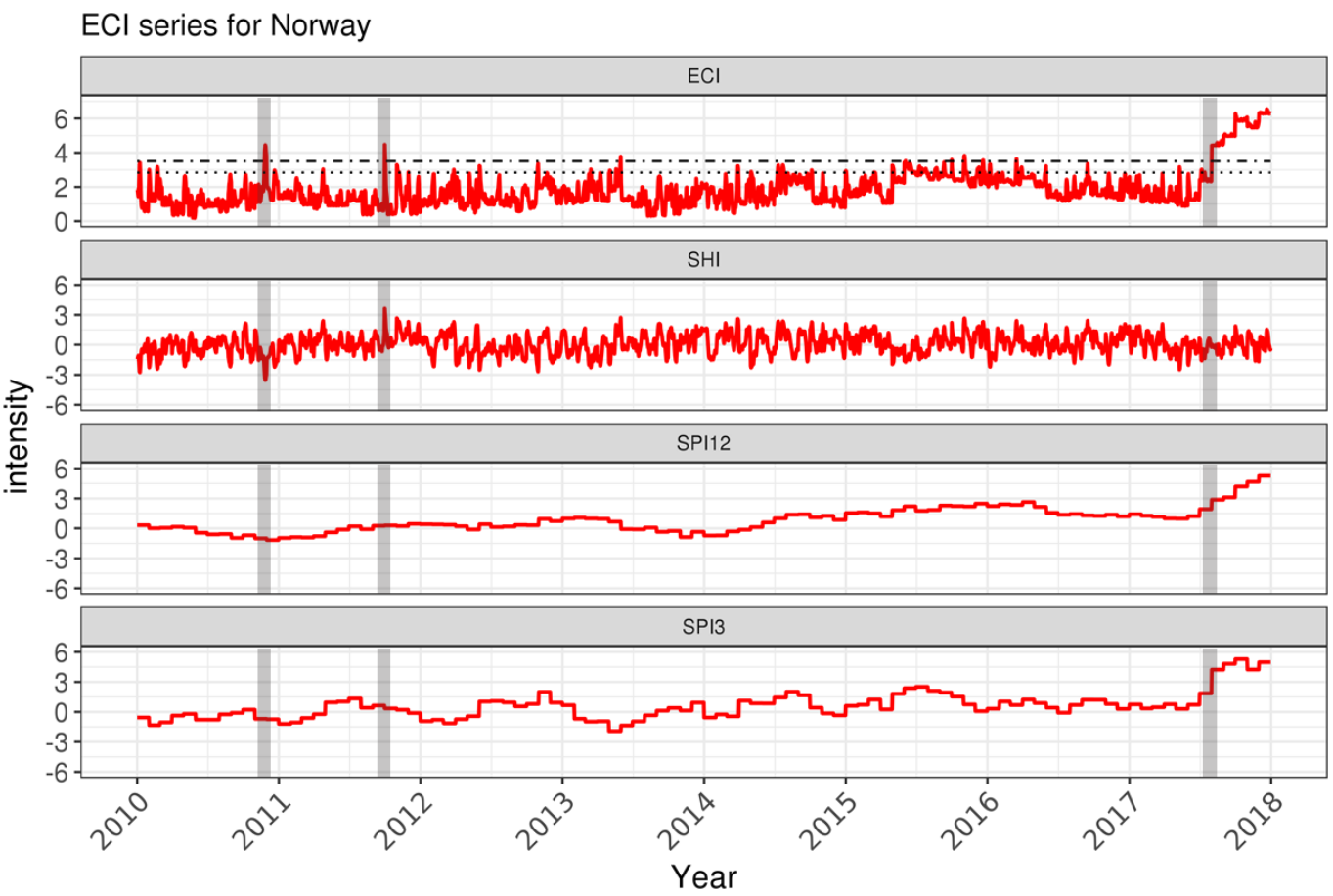

Figure 3: ECI and its components time series for Norway. Black lines denote the $95 \%$ (dot-dashed line) and 99\% (dotted line) ECI quantile thresholds.

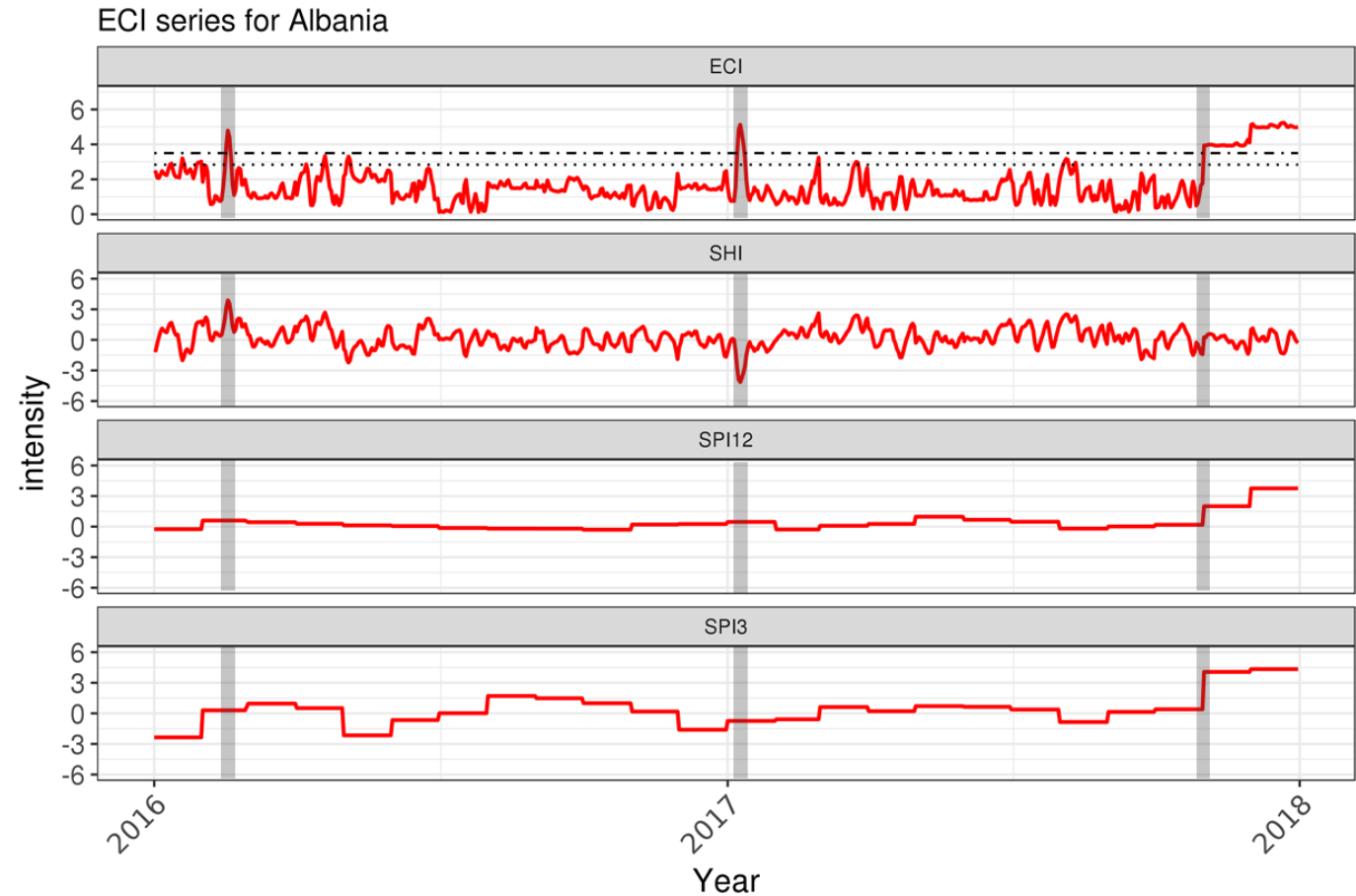

Figure 4: Same as figure 3 but for Albania, Balkan area, and over 2016-2017. 
Figure 5 depicts the time series for Italy, focused on the period 2016-2017. In this case, the heat wave which characterized the 2017 summer is clearly captured, with a ECI value equal to the $99 \%$ percentile threshold. It can be noticed that, the peak of ECI is mainly determined by the high value of the SHI index. The beginning of 2017, instead, was characterized by temperature lower than normal and persistent precipitations.

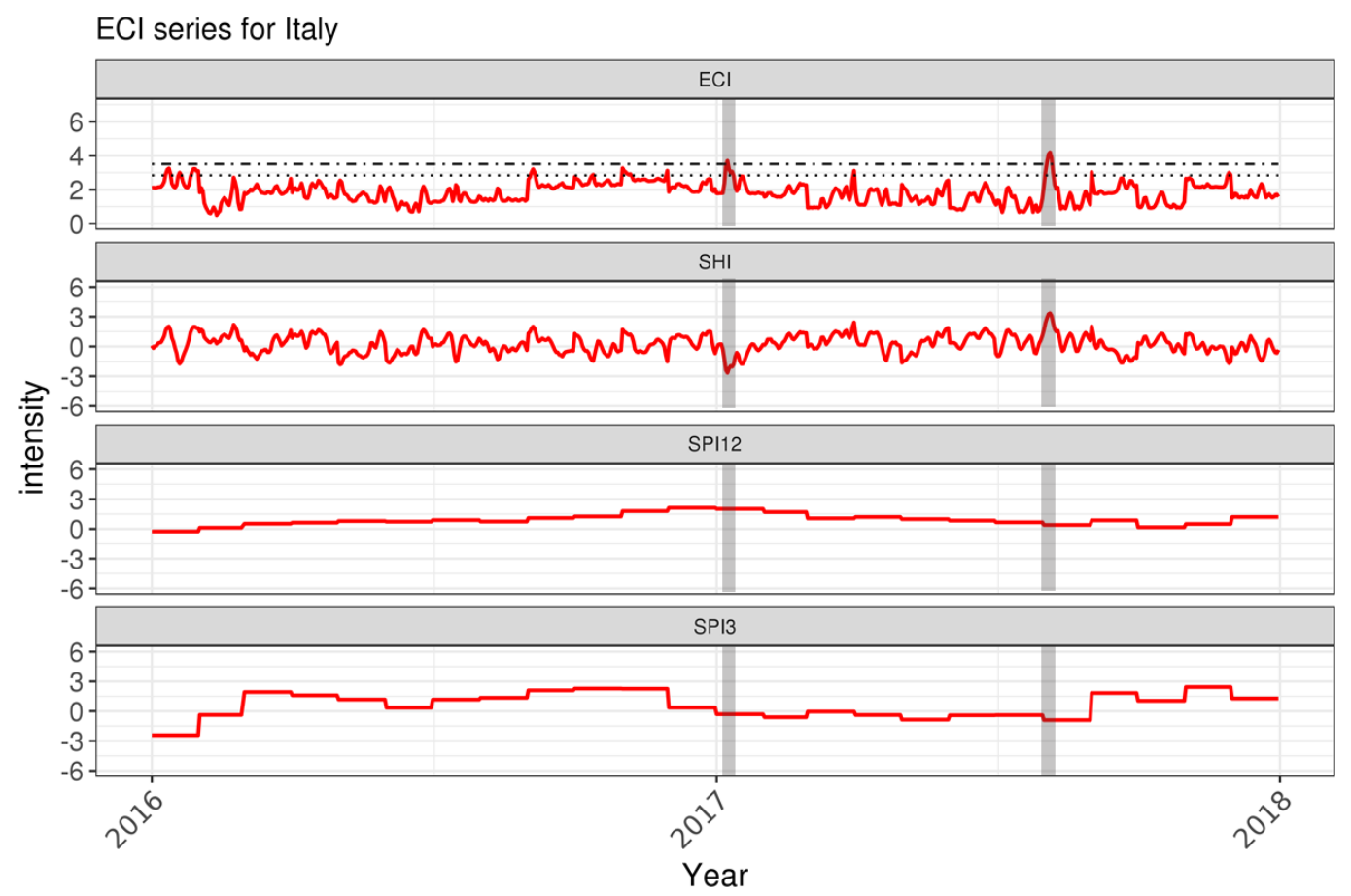

Figure 5: Same as figure 3 but for Italy and over 2016-2017.

\section{Conclusions}

We describe the application of a multi-hazard index, i.e. the Extreme Climate Index (ECI), across Europe. The index is defined by the combination of three different hazards indicators. We evaluated qualitatively the capability of the index to detect different types of extreme events, such as heat waves, droughts, and abundant precipitations, across diverse climate regimes. Extremes are defined according to percentile-based thresholds of ECI.

The spatial distribution of extremes captures the occurrence of the most severe and frequent events over the Mediterranean area and over northern Europe. The time series analysed over sample areas confirmed the flexibility of the index in capturing the different types of climate extremes, such as floods occurred in Norway and Albania at the end of the 2017 and the heat wave that hit the Mediterranean areas (including Italy) in summer 2017.

It is also possible to further calibrate the ECI for specific applications. For example, different time scales for the SPI components can be adopted. Additionally, a different calibration of the components may emphasize the detection of the heat-waves.

The promising results demonstrate the potential for ECI to be adopted as the underlying hazard index in climate risk management systems. The next step of the present work is adopting objective 
metrics (e.g., the Receiver Operating Characteristic, ROC, curves) to assess the global performance of the index in capturing observed events. Additionally, future work will regard the use of ECI to detect possible changes in the extreme occurrences due to global climate changes.

\section{References}

African Risk Capacity (2017). The Extreme Climate Index for XCF. Interim Report - Part 3, PO4800241750, 2017

Anagnostopoulou, C., Tolika, K., Lazoglou, G., and Maheras, P. (2017). The Exceptionally Cold January of 2017 over the Balkan Peninsula: A Climatological and Synoptic Analysis. Atmosphere 8, 252; doi:10.3390/atmos8120252

Arnone, E., Pumo, D., Viola, F., Noto, LV, La Loggia, G. (2013). Rainfall statistics changes in Sicily, Hydrol. Earth Syst. Sci., 17, 2013, 2449-2458

Cucchi, M., Petitta, M., Calmanti, S. (2017). The Extreme Climate Index: a novel and multihazard index for extreme weather events. Geophysical Research Abstracts Vol. 19, EGU2017-6761

Forestieri, A., Arnone, E., Blenkinsop, S., Noto, LV, Fowler, H. (2017). The impact of climate change on extreme precipitation in Sicily. Hydrological Processes, 10.1002/hyp.11421. 2017

International Federation of Red Cross And Red Crescent Societies (2017). Albania: Floods Emergency Plan of Action Operation n MDRAL007, Report Dec 2017

IPCC, Climate change (2013). The physical science basis. Contribution of Working Group I to the fifth assessment report of the Intergovernmental Panel on Climate Change. Cambridge University Press, Cambridge, United Kingdom and New York, NY, USA, 2013

Langsholt E., and Holmqvist, E. (2017). Norvegian Flood forecasting service (varsom.no). Rapport om flommen på Sфrlandet 30.9 - 3.10.2017, Rapport nr 80-2017

Mckee, TB., Doesken, NJ., Kleist, J. (1993). The relationship of drought frequency and duration to time scales. In Proceedings of the 8th Conference of Applied Climatology, 17-22 January, Anaheim, CA. American Meterological Society, Boston, MA, 1993, pp.179-184.

Norvegian Flood Forecasting Service (varsom.no) (2017). Styrtregn har ført til lokalt store skader på Vest-og Østlandet, Report, July2017

Russo, S. et al. (2014). Magnitude of extreme heat waves in present climate and their projection in a warming world. J. Geophys. Res. Atmos. 119, 12500-12512, 2014.

Wang, X., Yang, X., Liu, T., Li, F., Gao, R., Duan, L., Luo, Y. (2014) Trend and extreme occurrence of precipitation in a mid-latitude Eurasian steppe watershed at various time scales. 950 Hydrological Processes, 28(22), 5547-5560, 2014

Ward, J.H. (1963) Hierarchical grouping to optimize an objective function. Journal of the American Statistical Association, 58(301), 1963, 236-244.

Wilks, DS. (2006) Statistical Methods in the Atmospheric Sciences. Third Edition, International Geophysics series, vol. 100, 2006, ISBN 978-0-12-385022-5

World Weather Attribution (2017). Euro-Mediterranean Heat - Summer 2017. Report, September 2017 